\title{
BMJ Open Potentially addictive drugs dispensing to patients receiving opioid agonist therapy: a register-based prospective cohort study in Norway and Sweden from 2015 to 2017
}

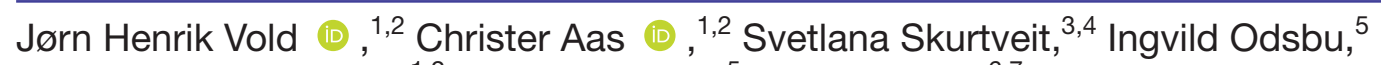
Fatemeh Chalabianloo,,$^{1,2}$ Johan Reutfors, ${ }^{5}$ Anne Halmøy, ${ }^{6,7}$ Kjell Arne Johansson, ${ }^{1,2}$ Lars Thore Fadnes (D) 1,2

To cite: Vold JH, Aas C, Skurtveit S, et al. Potentially addictive drugs dispensing to patients receiving opioid agonist therapy: a registerbased prospective cohort study in Norway and Sweden from 2015 to 2017. BMJ Open 2020;10:e036860. doi:10.1136/ bmjopen-2020-036860

- Prepublication history and additional material for this paper are available online. To view these files, please visit the journal online (http://dx.doi. org/10.1136/bmjopen-2020036860).

Received 08 January 2020 Revised 12 May 2020 Accepted 26 June 2020
Check for updates

(c) Author(s) (or their employer(s)) 2020. Re-use permitted under CC BY-NC. No commercial re-use. See rights and permissions. Published by BMJ.

For numbered affiliations see end of article.

Correspondence to Jørn Henrik Vold; jorn.vold@uib.no

\section{ABSTRACT}

Objectives To compare the use of benzodiazepines, zhypnotics, gabapentinoids, opioids and centrally acting stimulants (CAS) among patients who had received opioid agonist therapy (OAT) in Norway and Sweden during the period 2015 - 2017.

Design A register-based prospective cohort study using information about dispensed drugs from the Norwegian Prescription Database and Swedish Prescribed Drug Register.

Setting Patients who were dispensed OAT opioids from pharmacies.

Participants A total of 7176 Norwegian and 3591

Swedish patients on OAT were included.

Outcome measures The number and frequency of potentially addictive drugs dispensed were calculated for the two countries. The mean daily doses of dispensed benzodiazepines and z-hypnotics were summarised by calculating benzodiazepines in diazepam equivalents and z-hypnotics in zopiclone equivalents.

Results In $2017,46 \%$ of patients in Norway, and $15 \%$ in Sweden, were dispensed a benzodiazepine. Moreover, $14 \%$ in Norway and $26 \%$ in Sweden received z-hypnotics. Gabapentinoids were dispensed to $10 \%$ of patients in Norway and $19 \%$ of patients in Sweden. In Norway, $6 \%$ and $12 \%$ of the patients received strong and weak nonOAT opioids, respectively, whereas in Sweden 10\% were dispensed strong non-OAT opioids and $5 \%$ weak non-OAT opioids . CAS were dispensed to $4 \%$ in Norway and $18 \%$ in Sweden. The mean daily doses of benzodiazepines were 16 and $17 \mathrm{mg}$ diazepam equivalents in Norway and Sweden, respectively. For z-hypnotics, the mean daily dose was $8 \mathrm{mg}$ zopiclone equivalents in both countries. 'Benzodiazepines and z-hypnotics' was the most dispensed drug combination in 2017. Similar results were found in 2015 and 2016.

Conclusions Nearly half of those patients who were dispensed an OAT opioid in Norway and Sweden were dispensed potentially addictive drugs. The differences identified between Norway and Sweden might be related to differences in eligibility guidelines and restrictions with respect to OAT.

\section{Strengths and limitations of this study}

- This study used national register-based data of drugs dispensed from pharmacies in Norway and Sweden.

- This study did not capture patients who were dispensed opioid agonist therapy (OAT) opioids from entities other than pharmacies.

- There is potential for misclassification of patients if dispensed opioids were dispensed on medical indications other than OAT.

- About $40 \%$ and $10 \%$ of OAT patients in Sweden and Norway, respectively, were not identified by using these national register-based data.

\section{INTRODUCTION}

Several studies indicate that around $50 \%$ of those patients who receive opioid agonist therapy (OAT) are dispensed benzodiazepines (e.g., diazepam and oxazepam), z-hypnotics (zolpidem and zopiclone), gabapentinoids (pregabalin and gabapentin), non-OAT opioids (e.g., morphine and oxycodone) or centrally acting stimulants (CAS) (e.g., methylphenidate and lisdexamphetamine) yearly ${ }^{1-5}$, notwithstanding the use of any potentially addictive illicit drugs. ${ }^{1} 67$ Prescribing potentially addictive drugs to patients on OAT is controversial and comes with pros and cons. ${ }^{18}$ Combinations of several potentially addictive drugs may increase the risk of non-fatal or fatal overdoses, ${ }^{1}$ as well as amplify negative complex medical and psychosocial challenges such as unemployment, ${ }^{9}$ criminal behaviour ${ }^{10}$ and discontinuation of OAT. ${ }^{611-13}$ However, the majority of patients on OAT have psychiatric and physical comorbidities, including psychotic disorders, attention deficit 
hyperactivity disorder (ADHD), personality disorders, depression, other substance use disorders besides opioid addiction or injection-related diseases such as hepatitis C virus infection. ${ }^{14-16}$ The wide range of high-prevalent comorbidities can require coprescriptions of potentially addictive drugs to obtain an optimal medical treatment in the OAT population. Examples such as prescriptions of CAS in order to improve ADHD symptoms ${ }^{17}$ and shortterm prescriptions of benzodiazepines to treat psychomotor agitation caused by stimulant intoxications ${ }^{18}$ or seizure prophylaxis, as in cases of benzodiazepine or alcohol withdrawal, ${ }^{19}$ illustrate clinical indications for such coprescriptions.

The prevalence of potentially addictive drugs dispensed among patients on OAT varies between countries. ${ }^{15}{ }^{20-23}$ In the USA, in 2013, between $22 \%$ and $65 \%$ of patients on OAT were dispensed benzodiazepines, and $42 \%$ and $20 \%$ were dispensed benzodiazepines and z-hypnotics, respectively, in the UK between 1998 and 2014. ${ }^{20}{ }^{24}$ In Sweden, 41\% of OAT patients were dispensed z-hypnotics in the period 2005-2012. ${ }^{1}$ Furthermore, epidemiological studies have shown that a wide range of OAT patients, from $8 \%$ to $22 \%$, were dispensed gabapentinoids in different countries, ${ }^{1} 324$ while between $12 \%$ and $34 \%$ were dispensed non-OAT opioids. ${ }^{21} 2225$ In contrast, no studies have evaluated CAS dispensing among patients on OAT. Overall, there are substantial intercountry differences regarding patients on OAT who were dispensed potentially addictive drugs; however, there is a gap in knowledge concerning whether these differences still persist.

OAT has in recent decades been increasingly applied as an effective and well-documented treatment for opioid addiction. ${ }^{26-29}$ In Norway, around 7500 patients currently receive OAT, ${ }^{28}$ while the corresponding number for Sweden is nearly 4400 patients. ${ }^{30}$ Research on differences and similarities in the dispensing practice of potentially addictive drugs in these countries needs to be investigated to optimise the use of these drugs in the OAT population. In addition, evaluating dispensed doses of benzodiazepines, z-hypnotics, pregabalin, gabapentin and the CASs methylphenidate and lisdexamphetamine - the first hand of choice in the treatment of ADHD - are of particular interest due to the risk of overdoses and intoxications. It is also important for the study of possible variations in dispensed doses between the two countries.

Thus, this study aims to describe the rates and doses of potentially addictive drugs dispensed from Norwegian and Swedish pharmacies to patients receiving OAT in the period 2015-2017. We aim to describe the following:

1. The dispensing rates of benzodiazepines, z-hypnotics, gabapentinoids, non-OAT opioids and CAS per calendar year.

2. The mean daily doses of dispensed benzodiazepines, z-hypnotics, pregabalin, gabapentin, lisdexamphetamine and methylphenidate per calendar year.

3 . The most commonly dispensed combinations of potentially addictive drug groups: benzodiazepines, z-hypnotics, gabapentinoids, non-OAT opioids and/or CAS among patients on OAT in 2017.

\section{METHODS}

\section{Data sources}

Data were retrieved from the Norwegian Prescription Database and Swedish Prescribed Drug Register. From 1 January 2004 in Norway and 1 July 2005 in Sweden, all pharmacies are obliged to submit electronically all data regarding dispensed drugs to the Norwegian Prescription Database and Swedish Prescribed Drug Register. The Norwegian Prescription Database and Swedish Prescribed Drug Register are administered and regulated by the Norwegian Institute of Public Health and Swedish National Board of Health and Welfare, respectively. Both registers contain information on all drugs dispensed from pharmacies, with unique patient identifiers, except for drugs administered at hospitals, nursing homes and outpatient clinics. ${ }^{31} 32$ The Anatomical Therapeutic Chemical (ATC) classification system was used in accordance with the WHO standards per $2018 .{ }^{33}$ A recent report evaluating OAT stated that the Swedish Prescribed Drug Register identifies about $60 \%$ of patients on OAT, ${ }^{27}$ while the Norwegian Prescription Database is assumed to identify about $90 \%$ of the patients. ${ }^{28}$ Moreover, in 2016, Sweden changed the OAT eligibility criteria by including long-term use of opioids (not only opiates like heroin, opium and morphine) as analgesics for chronic, severe pain. ${ }^{26}{ }^{27}$ Inclusion criteria in this study, therefore, identified patients with a high opiate tolerance who had a high degree of continuity in their OAT treatment.

\section{Study population}

All patients between 18 and 75 years of age who received at least one mean defined daily dose (DDD) of one or more defined OAT opioids per day during 2015, 2016 or 2017 were included (see online supplementary table S1). A minimum of one mean DDD per day was set as a criterion for inclusion to exclude patients who were dispensed low-dosed OAT opioids on medical indications other than OAT. The DDD of OAT opioids was calculated for each calendar year separately, which means that patients were only included in the calendar year when the mean dispensed DDD per day of OAT opioids, measured in DDD divided by 365.25 days, was one or more. The type of OAT opioids that were the latest dispensed (calculated in DDD) per year determined which type of OAT opioid category the patients belonged to in a calendar year. Dispensing methadone tablets or injections as well as buprenorphine formulations (ATC code: N02AE01) that have other medical indications besides OAT in Norway and Sweden, were excluded in the calculation of mean DDD of OAT opioids per day.

\section{Patient and public involvement}

Patients and the public were not involved in the development of the study design, planning and recruitment. Study results were not distributed to the patients after 
the study. All data were handled strictly confidentially and anonymously. The Strengthening the Reporting of Observational Studies in Epidemiology Guidance checklist was applied during the preparation of the study.

\section{Definitions of OAT opioids, other potentially addictive drugs and drug groups}

All the potentially addictive drugs in the drug groups of benzodiazepines, z-hypnotics, gabapentinoids, OAT opioids, non-OAT opioids and CAS, which had marketing authorisations in Norway or Sweden in the period from 2015 to 2017, were included. All included drugs were defined according to their ATC codes. In addition, the non-OAT opioids were divided into two groups: 'strong non-OAT opioids' and 'weak non-OAT opioids' according to their analgesic potency.

\section{Analysis strategy and statistical analyses \\ Data analysis}

The age of included patients per year was calculated by subtracting the dispensing year from the birth year. The age of patients was categorised into four groups: 18-35, $36-45,46-55$ and 56-75.

The dispensing rates per year were defined as all included patients who were dispensed at least one potentially addictive drug during a calendar year divided by the number of included patients in the same year. The rates were calculated for each drug and the respective drug groups.

The mean daily doses per year of all dispensed benzodiazepines, z-hypnotics, pregabalin, gabapentin, lisdexamphetamine and methylphenidate were calculated by summing all dispensed DDD of each potentially addictive drug per calendar year in the study period. The DDD of each drug was converted to milligrams by using the definitions of the WHO Collaboration Centre for Drug Statistics Methodology (see online supplementary table S2). ${ }^{33}$ The dispensed doses (in milligrams) of each drug were divided by 365.25 days to calculate the mean daily doses per year. Further, the mean daily dose per year of each dispensed benzodiazepine was converted to mean daily dispensed diazepam equivalents according to the equivalency table stated by the Norwegian Directorate of Health and a study evaluating the equipotency of lorazepam versus diazepam (see online supplementary figure S1). ${ }^{34} 35$ The dispensed diazepam equivalents per day were used to calculate the total sum of all dispensed benzodiazepines per day per year. The mean daily doses of dispensed z-hypnotics were calculated by converting mean dispensed zolpidem dose per day to zopiclone equivalents according to the guidelines of the Norwegian Directorate of Health. ${ }^{34}$ Furthermore, the total mean doses per day of zopiclone and zolpidem in zopiclone equivalents for a calendar year were summed.

\section{Statistical analyses}

Means, medians, percentiles and percentages were used to calculate dispensing rates, and the dispensed doses of benzodiazepines, z-hypnotics, pregabalin, gabapentin, lisdexamphetamine and methylphenidate. Stata SE V.16.0 statistical software was used for all analyses.

\section{RESULTS}

\section{Descriptive characteristics}

A total of 7176 Norwegian and 3591 Swedish patients on OAT were included in the study period (table 1). In 2015, 6007 patients in Norway, and 2640 in Sweden fulfilled the inclusion criteria (see online supplementary figure S2). A further 5542 OAT patients in Norway, and 2683 OAT patients in Sweden were included in 2016, with 5556 Norwegian OAT patients and 2739 Swedish OAT patients having fulfilled the eligibility criteria in 2017 .

In 2017, $72 \%$ and $70 \%$ of the Norwegian and Swedish patients were male, respectively. The mean age of the patients included was 46 years in Norway and 45 years in Sweden. Buprenorphine/buprenorphine-naloxone was the most dispensed OAT opioid throughout the study period, having been dispensed to $55 \%$ of patients in Norway and $57 \%$ of patients in Sweden. The findings in 2015 and 2016 were similar.

\section{Dispensing rates of potentially addictive drugs}

In Norway, $56 \%$ of patients on OAT were dispensed benzodiazepines, z-hypnotics, gabapentinoids, non-OAT opioids or CAS in 2015 (table 2). In 2017, the proportion was 59\%. In Sweden, the proportion of patients on OAT who received at least one dispensation of these potentially addictive drugs was $56 \%$ in 2015 and $55 \%$ in 2017 (figure 1). In 2017, the proportion of patients receiving benzodiazepines was $46 \%$ in Norway and $15 \%$ in Sweden. Furthermore, $14 \%$ in Norway and 26\% in Sweden received z-hypnotics, and $10 \%$ of the Norwegian patients and $19 \%$ of the Swedish patients were dispensed gabapentinoids. CAS were dispensed to $4 \%$ of the Norwegian patients and $18 \%$ of the Swedish patients on OAT. Similar results were also achieved in 2015 and 2016 (see online supplementary figure S3).

Dispensed doses of benzodiazepines, z-hypnotics, gabapentin, pregabalin, lisdexamphetamine, and methylphenidate

In 2017, the mean doses of dispensed benzodiazepines were $17 \mathrm{mg}$ /day diazepam equivalents in Norway, with a corresponding $16 \mathrm{mg}$ /day in Sweden (table 3). Further, the mean dose of dispensed z-hypnotics was $8 \mathrm{mg} /$ day zopiclone equivalents in both countries in 2017. The mean daily doses of dispensed pregabalin, gabapentin and lisdexamphetamine were higher in Norway than in Sweden (pregabalin: $402 \mathrm{mg}$ vs $345 \mathrm{mg}$, gabapentin: $1021 \mathrm{mg}$ vs $772 \mathrm{mg}$ and lisdexamphetamine: $58 \mathrm{mg}$ vs $51 \mathrm{mg}$ ), while the mean dose of dispensed methylphenidate per day was higher in Sweden compared with Norway (methylphenidate: $80 \mathrm{mg}$ vs $57 \mathrm{mg}$ ). The results 
Table 1 Basic characteristics of patients receiving opioid agonist therapy in Norway and Sweden

\begin{tabular}{|c|c|c|c|c|c|c|c|c|c|c|c|c|}
\hline \multirow[b]{3}{*}{ Baseline characteristics } & \multicolumn{4}{|l|}{2015} & \multicolumn{4}{|l|}{2016} & \multicolumn{4}{|l|}{2017} \\
\hline & \multicolumn{2}{|c|}{ Norway } & \multicolumn{2}{|c|}{ Sweden } & \multicolumn{2}{|c|}{ Norway } & \multicolumn{2}{|c|}{ Sweden } & \multicolumn{2}{|c|}{ Norway } & \multicolumn{2}{|c|}{ Sweden } \\
\hline & No. & $\%$ & No. & $\%$ & No. & $\%$ & No. & $\%$ & No. & $\%$ & No. & $\%$ \\
\hline \multicolumn{13}{|l|}{ Age } \\
\hline$\geq 18-35$ & 1132 & 19 & 648 & 25 & 958 & 17 & 649 & 24 & 881 & 16 & 647 & 24 \\
\hline$>45-55$ & 2096 & 35 & 737 & 28 & 1961 & 35 & 708 & 26 & 2000 & 36 & 713 & 26 \\
\hline$>55-\leq 75$ & 736 & 12 & 469 & 18 & 808 & 15 & 520 & 19 & 924 & 17 & 560 & 20 \\
\hline Mean (SD) & \multicolumn{2}{|c|}{$45(9)$} & \multicolumn{2}{|c|}{$44(11)$} & \multicolumn{2}{|c|}{$45(9)$} & \multicolumn{2}{|c|}{$45(11)$} & \multicolumn{2}{|c|}{$46(9)$} & \multicolumn{2}{|c|}{$45(11)$} \\
\hline \multicolumn{13}{|l|}{ Gender } \\
\hline Male & 4225 & 70 & 1886 & 71 & 3897 & 70 & 1939 & 72 & 3878 & 70 & 1961 & 72 \\
\hline \multicolumn{13}{|l|}{ OAT opioids* } \\
\hline Methadone/levomethadone & 2747 & 46 & 1229 & 47 & 2389 & 43 & 1209 & 45 & 2533 & 46 & 1191 & 43 \\
\hline Buprenorphine/buprenorphine-naloxone & 3260 & 54 & 1411 & 53 & 3153 & 57 & 1474 & 55 & 3023 & 54 & 1548 & 57 \\
\hline
\end{tabular}

*Patients were categorised in the groups 'Methadone/Levomethadone' and 'Buprenorphine/buprenorphine-naloxone'. The type of OAT opioids was calculated based on the most dispensed OAT opioid measured in DDD per calendar year. DDD, defined daily dose; No., number of patients; OAT, opioid agonist therapy.

were relatively similar in 2015 and 2016 except for the mean dose of dispensed lisdexamphetamine per day, which was higher (in $\mathrm{mg}$ ) in Sweden than in Norway in 2015 (lisdexamphetamine: $42 \mathrm{mg}$ vs $13 \mathrm{mg}$ ).

\section{Combinations of potentially addictive drugs in 2017}

The proportion of patients on OAT being dispensed a single potentially addictive drug was $34 \%$ in Norway and $31 \%$ in Sweden. A quarter were dispensed potentially addictive drugs from two or more drug groups (see online supplementary table S3). 'Benzodiazepines and z-hypnotics' was the most commonly dispensed combination of drugs, whereas 'benzodiazepines and nonOAT opioids' and 'z-hypnotics and gabapentinoids' were the second most common combinations in Norway and Sweden, respectively.

\section{DISCUSSION}

The proportion of patients on OAT who were dispensed a potentially addictive drug was unchanged during the study period, with about half of the patients in both countries. There were, however, substantial variations between the countries in all dispensed drug groups. Benzodiazepines and weak non-OAT opioids were more commonly dispensed in Norway than in Sweden. In contrast, z-hypnotics, gabapentinoids, CAS and strong non-OAT opioids were more frequently dispensed in Sweden compared with Norway. Similar variations between Norway and Sweden have also been found regarding dispensing weak and strong non-OAT opioids in the general population. ${ }^{36}$ The most frequent combinations of potentially addictive drugs with OAT medications in 2017 were observed for benzodiazepines and z-hypnotics in both countries. The mean daily doses of dispensed benzodiazepines and z-hypnotics were also similar between the countries, while pregabalin, gabapentin and lisdexamphetamine doses were higher (in $\mathrm{mg}$ ) in Norway. The mean daily dose of methylphenidate was higher (in $\mathrm{mg}$ ) in Sweden compared with Norway. Similar results were found in 2015 and 2016.

The Swedish OAT guidelines recommend restrained practice in dispensing potentially addictive drugs, ${ }^{26}{ }^{27}$ while Norway goes further by downright discouraging benzodiazepine use in OAT. It was, therefore, particularly surprising that only $15 \%$ of the patients in Sweden were dispensed benzodiazepines, whereas, in Norway, benzodiazepines were dispensed to about half of the OAT patients. However, the dispensing rates of z-hypnotics and gabapentinoids were higher in Sweden than in Norway. The fact that the prevalence of mental and physical disorders is high among patients on OAT - and that there is a broad spectrum of medical indications for the use of benzodiazepines, gabapentinoids and z-hypnotics - makes it challenging to determine whether our results point towards inappropriate dispensing practice in the OAT populations in each country. ${ }^{14}{ }^{15}{ }^{37-39}$ It is nevertheless noteworthy that the dispensing rates of these drugs deviated considerably between the two countries.

Sweden had dispensing rates nearly four times higher for CAS compared with Norway, which indicates that coverage of ADHD treatment in patients on OAT is higher in Sweden. In both countries, guidelines for ADHD treatment recommend abstinence from other potentially addictive drugs when CAS are dispensed to patients on $\mathrm{OAT}^{40}$ In addition, the Norwegian guidelines recommend 


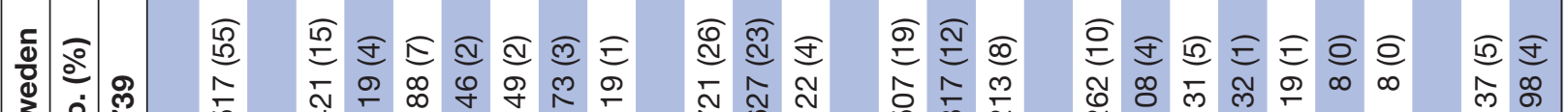

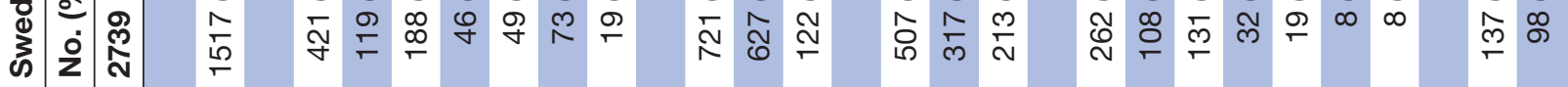

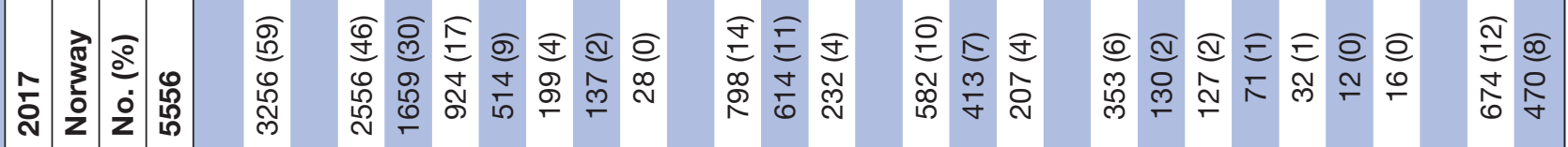

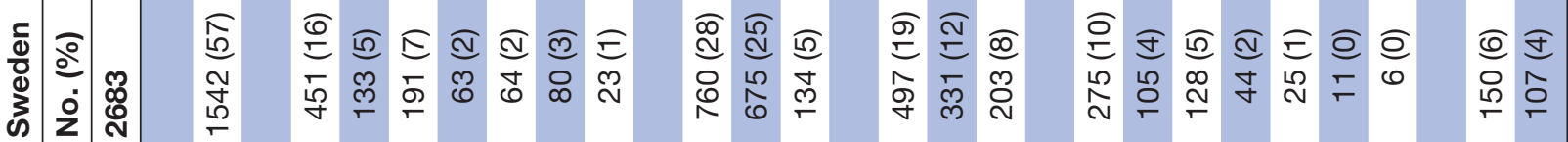

$\frac{\sqrt{0}}{\frac{0}{0}}$

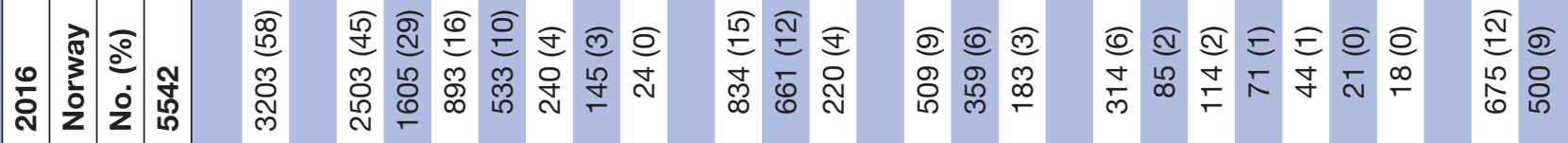
응

응

$\stackrel{\frac{?}{2}}{\frac{2}{0}}$

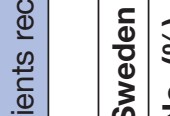

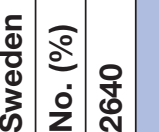

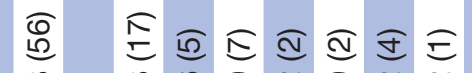

$\stackrel{\infty}{\underset{\sim}{+}}$

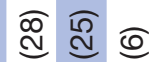

员兽京

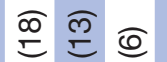

尊吕志

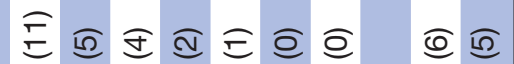

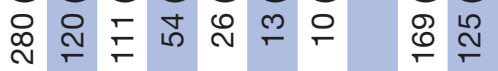

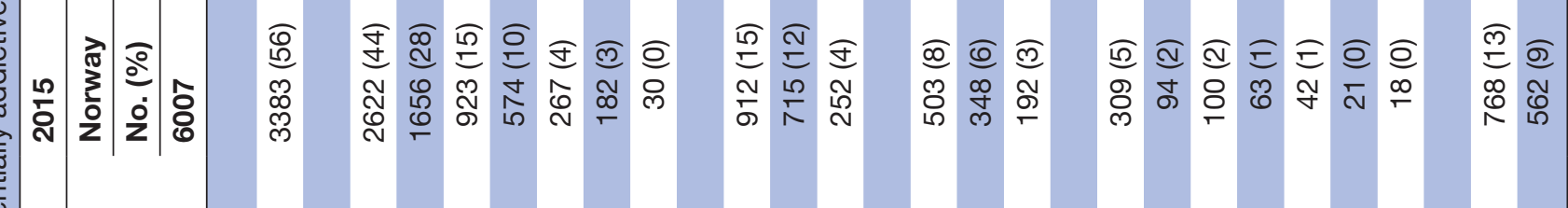<smiles>CCC</smiles>
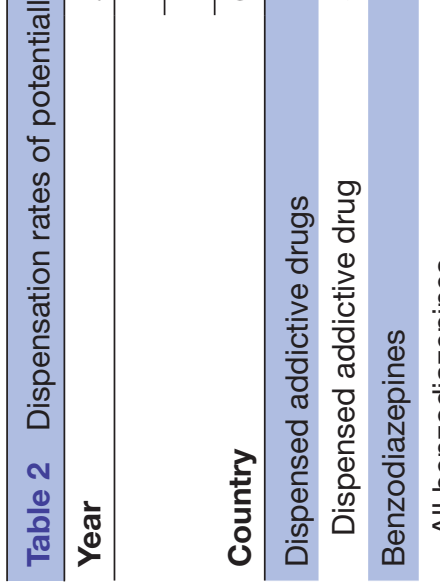

$\stackrel{\mathscr{0}}{\stackrel{0}{0}}$

2)

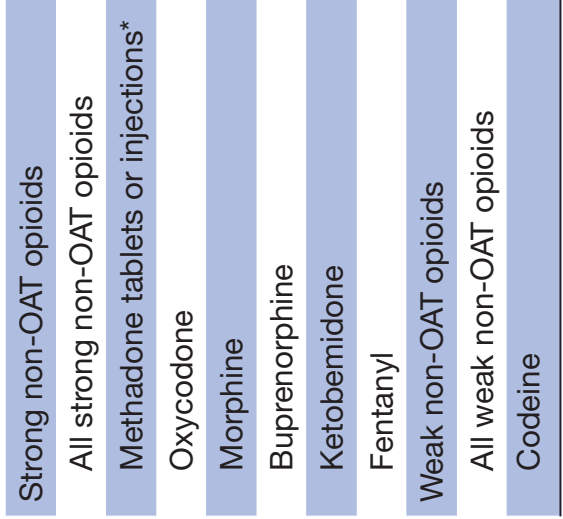




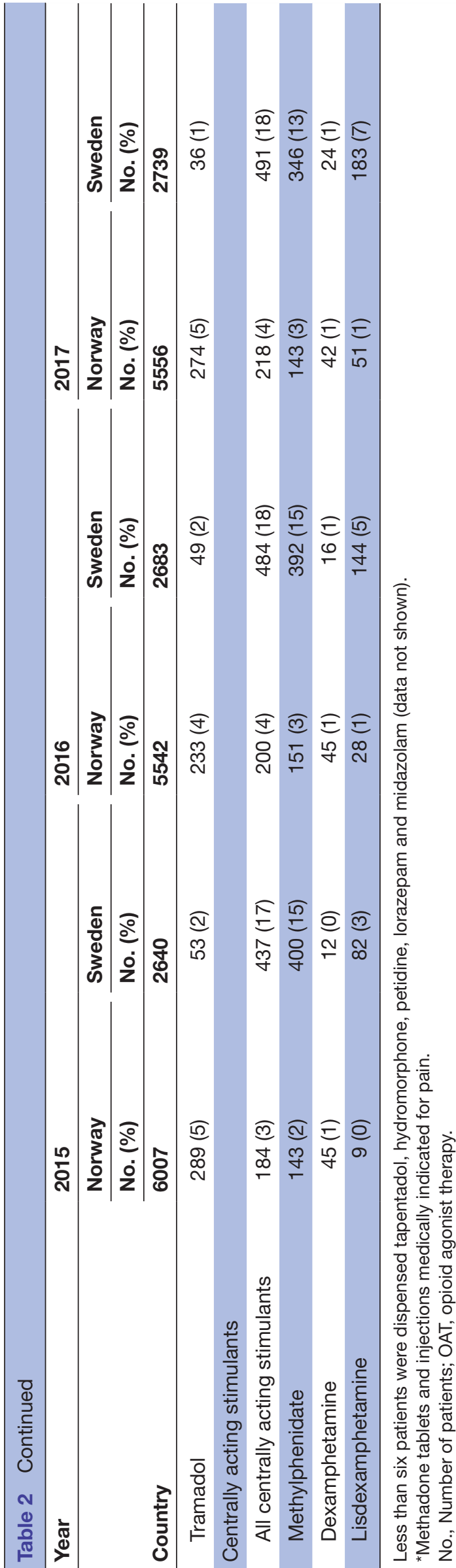

documented abstinence from potentially addictive drugs at least 3 months prior to the initiation of CAS in OAT patients when indicated. ${ }^{41}$ This may partly explain a lower dispensing rate of CAS in Norway compared with Swedish OAT patients. Furthermore, unlike Norway, Sweden seems to terminate OAT in cases of repeated illicit drug use, which indicates that the coverage of OAT among patients with severe opioid addiction may be lower in Sweden. ${ }^{3042}$ This can explain why the proportion of OAT patients who meet the criteria for codispensing CAS is higher in Sweden compared with Norway.

The differences in dispensing rates and mean daily doses of codispensed potentially addictive drugs between Norway and Sweden may also be explained by the composition and heterogeneity of OAT populations. The European Monitoring Centre for Drugs and Drug Addiction, evaluating OAT in 12 European countries, ${ }^{29}$ points out that restrictive policy, narrow inclusion criteria and costs are seen as substantial challenges limiting the coverage of OAT. In general, patients who repeatedly use illicit drugs in OAT have more psychiatric and somatic comorbidities. ${ }^{43-45}$ In Sweden, repeated use of illicit drugs in OAT may cause patients to be terminated from OAT against their will. ${ }^{42}$ This is to believe that Norway probably has a higher coverage of OAT, which also includes patients using illegal drugs and, accordingly, those with a higher burden of comorbid diseases. In addition, the divergent dispensing practices in the two countries could reflect the lack of consensus and evidence-bases concerning the treatment of underlying disorders in OAT patients.

Moreover, a tenth of the Norwegian OAT patients were dispensed a gabapentinoid in 2017, whereas nearly twice as many were dispensed this drug in Sweden. During the last decade, the dispensing of gabapentinoids has increased substantially in the general population in Norway and Sweden despite studies that point out that gabapentinoids are potentially addictive. ${ }^{724313246}$ Systematic reviews evaluating the use of gabapentinoids indicate that patients with opioid addiction were at a particular risk of misusing pregabalin and gabapentin, ${ }^{746}$ and euphoria and sedative effects were described when combining with opioids. Therefore, it is worrying that dispensing rates of gabapentinoids were high and increasing among patients on OAT.

Overall, based on our data and existing knowledge, we are unable to sufficiently evaluate whether dispensing rates of potentially addictive drugs were disproportionately high or even low among patients on OAT in Norway and Sweden during the study period. Some patients may have been undertreated considering their high burden of disease. On the other hand, a recent study has found that being dispensed gabapentinoids, z-hypnotics or benzodiazepines is associated with overdose death among patients on OAT. ${ }^{1}$ To stay on the safe side of this challenging matter, lower dispensing rates of these drugs may be preferable considering a high number of overdose deaths in Norway and Sweden during the last decade..$^{3047}$ Stricter dispensing practices with clearer defined medical 


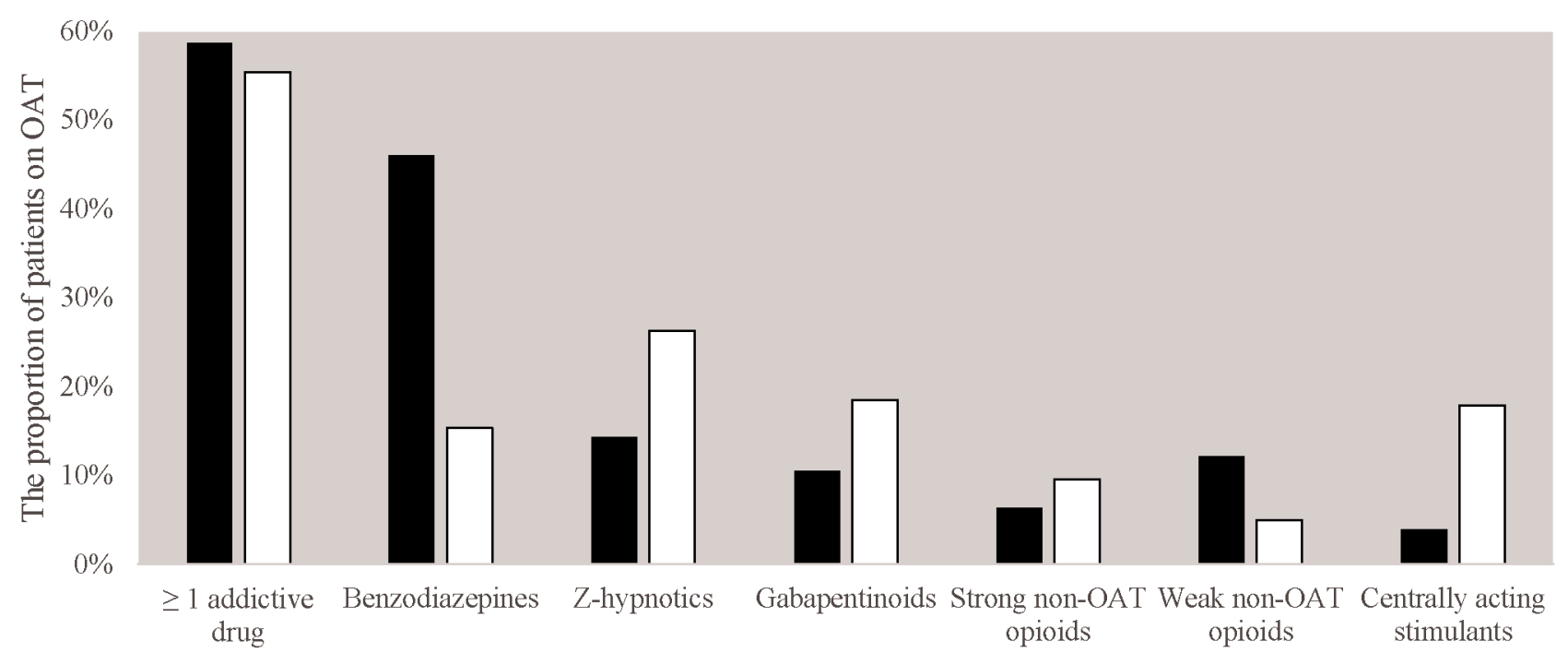

- Norway $\square$ Sweden

Figure 1 The proportion of patients on OAT who were dispensed potentially addictive drugs in 2017. The figure displays the proportion of patients on OAT who were dispensed at least one potentially addictive drug, benzodiazepine, z-hypnotic, gabapentinoid, strong non-OAT opioid, weak non-OAT opioid and centrally acting stimulant in Norway and Sweden in 2017. Strong non-OAT opioids were defined as all opioid expect codeine, tramadol and tapentadol. Weak non-OAT opioids were defined as all drugs that contain codeine, tramadol or tapentadol. OAT, opioid agonist therapy.

indications, regular urine testing to prevent concomitant street drug use, and close collaboration between prescribers of OAT opioids and those dispensing potentially addictive drugs may be important measures to decrease future overdose deaths and ensure more reasonable and safe treatment approaches among the highly morbid patients on OAT.

\section{STRENGTHS AND LIMITATIONS}

The use of national registry data has some advantages, as it can capture whole cohorts of the studied populations. The Norwegian Prescription Database and Swedish Prescribed Drug Register have advantages in that they receive all information concerning dispensed drugs from pharmacies in Norway and Sweden, except for those administered at hospitals, nursing homes and outpatient clinics. These registers are the most useful databases that identify reliable information regarding drug dispensing among patients on OAT. ${ }^{31} 32$

However, this study also has some limitations, mainly related to possible differences in selection bias between the studied populations. First, in both countries, patients may use methadone mixture for a medical indication other than OAT yet still be included in the OAT population. To account for this, only patients who had been dispensed a mean dose of one or more DDD of methadone mixture, levomethadone or buprenorphine/ buprenorphine-naloxone during a calendar year were included. Second, mean daily doses were calculated by summing all dispensed doses of the respective drugs during a calendar year divided by 365.25 days. Dividing the dispensed doses per year by 365.25 have some limitations. Some patients may have been dispensed drugs in a higher mean daily dose within a shorter period than the calculations of mean daily doses per year indicate. Further, the drugs that were dispensed at the end of December for consumption in the following months were calculated as consumed in the year the drugs were dispensed. The latter could potentially signify that the mean daily doses were calculated higher than the dose recommended by the prescribers. Third, it is estimated that only about $60 \%$ of patients on OAT are identified through the Swedish Prescribed Drug Register; the remaining proportion may receive OAT opioids from specialised addiction outpatient clinics within specialist healthcare.$^{27}$ In Norway, it is estimated that $90 \%$ of patients who were dispensed OAT opioids were registered in the Norwegian Prescription Database. ${ }^{28}$ The fact that $40 \%$ of the Swedish patients were lacking could skew the results and affect the conclusion. Patients who received OAT opioids from outpatient clinics may have more psychiatric and physical comorbidities and need more follow-ups than patients who were dispensed OAT opioids by pharmacies. Therefore, these comorbid patients who could not be captured by our study may have had higher dispensing rates of potentially addictive drugs, meaning that the dispensing rates may have been underestimated in this study. Fourth, the Swedish Prescribed Drug Register does not provide data on patients who died during the study period. Due to this, patients were censored from the year with no dispensing 
Open access

Table 3 Dispensed dose of potentially addictive drugs in the period from 2015 to 2017

\begin{tabular}{|c|c|c|c|c|c|}
\hline Year & 2015 & & 2016 & & 2017 \\
\hline Country & Norway & Sweden & Norway & Sweden & Norway \\
\hline
\end{tabular}

Benzodiazepines

Diazepam equivalents

\begin{tabular}{|c|c|c|c|c|c|c|}
\hline Number of patients & 2622 & 438 & 2503 & 451 & 2556 & 421 \\
\hline Mean (mg/year) & 6920 & 6896 & 6585 & 6437 & 6216 & 5936 \\
\hline Mean (mg/day/year) & 19 & 19 & 18 & 18 & 17 & 16 \\
\hline 25 percentile (mg/day/year) & 3 & 2 & 3 & 2 & 3 & 2 \\
\hline 75 percentile (mg/day/year) & 21 & 22 & 21 & 21 & 20 & 21 \\
\hline \multicolumn{7}{|l|}{ Zopiclone equivalents } \\
\hline Number of patients & 912 & 750 & 834 & 760 & 798 & 721 \\
\hline Mean (mg/year) & 2867 & 3037 & 2904 & 2951 & 2942 & 3008 \\
\hline Mean (mg/day/year) & 8 & 8 & 8 & 8 & 8 & 8 \\
\hline Median (mg/day/year) & 5 & 7 & 6 & 6 & 6 & 7 \\
\hline \multicolumn{7}{|l|}{ Gabapentin } \\
\hline Number of patients & 192 & 164 & 183 & 203 & 207 & 213 \\
\hline Mean (mg/year) & 335409 & 256505 & 334730 & 276083 & 372966 & 282017 \\
\hline Mean (mg/day/year) & 918 & 702 & 916 & 755 & 1021 & 772 \\
\hline Median (mg/day/year) & 376 & 324 & 492 & 329 & 492 & 329 \\
\hline 25 percentile (mg/day/year) & 82 & 82 & 82 & 82 & 164 & 82 \\
\hline 75 percentile (mg/day/year) & 1287 & 992 & 1232 & 986 & 1203 & 986 \\
\hline \multicolumn{7}{|l|}{ Pregabalin } \\
\hline
\end{tabular}

Centrally acting stimulants

\begin{tabular}{|c|c|c|c|c|c|c|}
\hline \multicolumn{7}{|l|}{ Methylphenidate } \\
\hline Number of patients & 143 & 400 & 151 & 392 & 143 & 346 \\
\hline Mean (mg/year) & 18957 & 28966 & 21364 & 29248 & 20845 & 29305 \\
\hline Median (mg/day/year) & 48 & 69 & 52 & 71 & 57 & 70 \\
\hline 25 percentile (mg/day/year) & 16 & 35 & 18 & 31 & 20 & 28 \\
\hline \multicolumn{7}{|l|}{ Lisdexamphetamine } \\
\hline Number of patients & 9 & 82 & 28 & 144 & 51 & 183 \\
\hline Mean (mg/year) & 4778 & 15238 & 18158 & 17649 & 21033 & 18514 \\
\hline Mean (mg/day/year) & 13 & 42 & 50 & 48 & 58 & 51 \\
\hline Median (mg/day/year) & 14 & 29 & 37 & 42 & 42 & 48 \\
\hline
\end{tabular}

Continued 
Table 3 Continued

\begin{tabular}{|c|c|c|c|c|c|c|}
\hline Year & 2015 & & 2016 & & 2017 & \\
\hline Country & Norway & Sweden & Norway & Sweden & Norway & Sweden \\
\hline 25 percentile (mg/day/year) & 2 & 11 & 14 & 21 & 20 & 20 \\
\hline
\end{tabular}

The table displays the mean doses and mean daily doses of dispensed benzodiazepines, z-hypnotics, pregabalin, gabapentin, methylphenidate and lisdexamphetamine per calendar year in the period from 2015 to 2017. The mean daily dose of each drug was calculated by summarising all dispensed DDD per year. The summarised DDD were converted to milligrams according to the WHOs standard. In addition, for benzodiazepines and z-hypnotics, all doses of dispensed benzodiazepines were converted into diazepam equivalents and z-hypnotics into zopiclone equivalents. We used equipotency tables from the Norwegian Directorate of Health ${ }^{34}$ and a study evaluating the equipotency of lorazepam vs diazepam ${ }^{35}$ when calculating the doses to diazepam and zopiclone equivalents. Further, all dispensed doses (benzodiazepines, z-hypnotics, gabapentin, pregabalin, methylphenidate and lisdexamphetamine) per year were divided by 365.25 days to calculate the mean and median daily doses, and the daily doses at the 25 percentile, and the 75 percentile.

OAT opioids in both countries. The annual self-reported survey on the Norwegian OAT population indicated that the death rate is approximately $1.5 \%$ per 100 patientyear, which could constitute about 125 patients yearly in our Norwegian and Swedish population. ${ }^{28}$ Fifth, because no dispensed drugs in Sweden nor all non-reimbursed dispensations in Norway are necessarily linked to medical diagnostic codes, such as the International Statistical Classification of Diseases and Related Health Problems version 10, or the International Classification of Primary Care, the medical indications for the dispensations are not available to the researchers through the prescription register-based databases. Sixth, in 2016, Sweden changed the inclusion criteria to be granted OAT by including opioid-addicted patients with extensive opioid use caused by chronic severe pain. ${ }^{26}{ }^{27}$ The proportion of patients receiving OAT opioids due to pain was not estimated in this study.

\section{CONCLUSION}

About half of patients who were dispensed an OAT opioid were codispensed potentially addictive drugs in Norway and Sweden. There were remarkable differences in the dispensing rates and dispensed doses of potentially addictive drugs between OAT patients in these countries. This might be related to differences in national guidelines, a lack of evidence-based knowledge and international consensus on the treatment of comorbid conditions among patients on OAT or differences in the criteria required to be included and kept in OAT, which again may contribute to varying clinical practice and treatment approaches in OAT populations across the countries. We call for further research to investigate proper approaches for the treatment of comorbid conditions in patients undergoing OAT.

\footnotetext{
Author affiliations

${ }^{1}$ Department of Addiction Medicine, Haukeland University Hospital, Bergen, Norway ${ }^{2}$ Department of Global Public Health and Primary Care, University of Bergen, Bergen, Norway

${ }^{3}$ Department of Mental Disorders, Norwegian Institute of Public Health, Oslo, Norway

${ }^{4}$ Norwegian Centre for Addiction Research, University of 0slo, 0slo, Norway
}

${ }^{5}$ Department of Medicine, Karolinska Institutet, Stockholm, Sweden ${ }^{6}$ Department of Clinical Medicine, University of Bergen, Bergen, Norway ${ }^{7}$ Division of Psychiatry, Haukeland University Hospital, Bergen, Norway

Contributors JHV led the analysis and was involved in the study design and writing of the article. CFA, SS, IO, FC, JR, AH, KAJ and LTF contributed to the study design, analysis, and writing of the article. All authors have read and approved the final article.

Funding The study was funded by The Norwegian Research Council (BEHANDLING, contract no 269855) and the Western Norway Regional Health Authority ('Åpen prosjektstøtte') with the Department of Addiction Medicine, Haukeland University Hospital as the responsible institution. The funders had no role in the study design, data collection and analysis, decision to publish or preparation of the manuscript. Two of the authors are funded from the research grant BEHANDLING related to the project INTRO-HCV from the Norwegian Research Council. The other authors are funded by their respective affiliations.

Competing interests 10 and JR are employed at the Centre for Pharmacoepidemiology, Karolinska Institute, which receives grants from several entities (pharmaceutical companies, regulatory authorities and contract research organisations) for performance of drug safety and drug utilisation studies, unrelated to this work.

Patient consent for publication Not required.

Ethics approval The Regional Committee for Medical and Health Research Ethics West, Norway, and the Swedish Ethical Review Authority in Stockholm, Sweden, have both approved the use of the Norwegian and Swedish registry data for the study (Norway: reference number 2018/939/REK Vest, 19 June 2018; Sweden: reference number 2018/2080-31/1, 14 November 2018 and reference number 2019-04791, 22 November 2019). The Regional Committee for Medical and Health Research Ethics West, Norway, is appointed by the Norwegian Ministry of Education and Research, and the Swedish Ethical Review Authority is under the Swedish Ministry of Education. No informed consent from the patients was necessary.

Provenance and peer review Not commissioned; externally peer reviewed.

Data availability statement Apart from supplemental tables with some additional data, no additional data are available due to data protection requirements.

Open access This is an open access article distributed in accordance with the Creative Commons Attribution Non Commercial (CC BY-NC 4.0) license, which permits others to distribute, remix, adapt, build upon this work non-commercially, and license their derivative works on different terms, provided the original work is properly cited, appropriate credit is given, any changes made indicated, and the use is non-commercial. See: http://creativecommons.org/licenses/by-nc/4.0/.

\section{ORCID iDs}

Jørn Henrik Vold http://orcid.org/0000-0001-8701-7638

Christer Aas http://orcid.org/0000-0002-6469-9354

Lars Thore Fadnes http://orcid.org/0000-0001-8757-2092 


\section{REFERENCES}

1 Abrahamsson T, Berge J, Öjehagen A, et al. Benzodiazepine, z-drug and pregabalin prescriptions and mortality among patients in opioid maintenance treatment-a nation-wide register-based open cohort study. Drug Alcohol Depend 2017;174:58-64.

2 Vold JH, Aas C, Skurtveit S, et al. Dispensation of attention deficit hyperactivity disorder (ADHD) medications in patients receiving opioid agonist therapy; a national prospective cohort study in Norway from 2015 to 2017. BMC Psychiatry 2020;20:119.

3 Vold JH, Skurtveit S, Aas C, et al. Dispensations of benzodiazepines, z-hypnotics, and gabapentinoids to patients receiving opioid agonist therapy; a prospective cohort study in Norway from 2013 to 2017. BMC Health Serv Res 2020;20:352.

4 Jones JD, Mogali S, Comer SD. Polydrug abuse: a review of opioid and benzodiazepine combination use. Drug Alcohol Depend 2012;125:8-18.

5 Bramness JG, Kornør H. Benzodiazepine prescription for patients in opioid maintenance treatment in Norway. Drug Alcohol Depend 2007;90:203-9.

6 European Monitoring Centre for Drugs and Drug Addiction. The misuse of benzodiazepines among high-risk opioid users in Europe, 2018. Available: http://www.emcdda.europa.eu/system/files/ publications/2733/Misuse\%20of\%20benzos_POD2015.pdf

7 Evoy KE, Morrison MD, Saklad SR. Abuse and misuse of pregabalin and gabapentin. Drugs 2017;77:403-26.

8 Bakker A, Streel E. Benzodiazepine maintenance in opiate substitution treatment: good or bad? A retrospective primary care case-note review. J Psychopharmacol 2017;31:62-6.

9 Bleich A, Gelkopf M, Schmidt V, et al. Correlates of benzodiazepine abuse in methadone maintenance treatment. A 1 year prospective study in an Israeli clinic. Addiction 1999;94:1533-40.

10 Bleich A, Gelkopf M, Weizman T, et al. Benzodiazepine abuse in a methadone maintenance treatment clinic in Israel: characteristics and a pharmacotherapeutic approach. Isr J Psychiatry Relat Sci 2002;39:104-12.

11 Eiroa-Orosa FJ, Haasen C, Verthein U, et al. Benzodiazepine use among patients in heroin-assisted vs. methadone maintenance treatment: findings of the German randomized controlled trial. Drug Alcohol Depend 2010;112:226-33.

12 Franklyn AM, Eibl JK, Gauthier G, et al. The impact of benzodiazepine use in patients enrolled in opioid agonist therapy in northern and rural Ontario. Harm Reduct J 2017;14:6.

13 Brands B, Blake J, Marsh DC, et al. The impact of benzodiazepine use on methadone maintenance treatment outcomes. J Addict Dis 2008;27:37-48.

14 Lai HMX, Cleary M, Sitharthan T, et al. Prevalence of comorbid substance use, anxiety and mood disorders in epidemiological surveys, 1990-2014: a systematic review and meta-analysis. Drug Alcohol Depend 2015;154:1-13.

15 Callaly T, Trauer T, Munro L, et al. Prevalence of psychiatric disorder in a methadone maintenance population. Aust N Z J Psychiatry 2001;35:601-5.

16 Platt L, Minozzi S, Reed J, et al. Needle syringe programmes and opioid substitution therapy for preventing hepatitis $C$ transmission in people who inject drugs. Cochrane Database Syst Rev 2017;9:CD012021.

17 Levin FR, Mariani JJ, Specker S, et al. Extended-release mixed amphetamine salts vs placebo for comorbid adult attention-deficit/ hyperactivity disorder and cocaine use disorder. JAMA Psychiatry 2015;72:593-602.

18 Parr JM, Kavanagh DJ, Cahill L, et al. Effectiveness of current treatment approaches for benzodiazepine discontinuation: a metaanalysis. Addiction 2009;104:13-24.

19 Amato L, Minozzi S, Vecchi S, et al. Benzodiazepines for alcohol withdrawal. Cochrane Database Syst Rev 2010;3:CD005063.

20 Zhu Y, Coyle DT, Mohamoud M, et al. Concomitant use of buprenorphine for medication-assisted treatment of opioid use disorder and benzodiazepines: using the prescription behavior surveillance system. Drug Alcohol Depend 2018;187:221-6.

21 Fredheim OMS, Borchgrevink PC, Nordstrand B, et al. Prescription of analgesics to patients in opioid maintenance therapy: a pharmacoepidemiological study. Drug Alcohol Depend 2011;116:158-62.

22 Nosyk B, Fischer B, Sun $\mathrm{H}$, et al. High levels of opioid analgesic co-prescription among methadone maintenance treatment clients in British Columbia, Canada: results from a population-level retrospective cohort study. Am J Addict 2014;23:257-64.
23 Abel KF, Bramness JG, Martinsen EW. Stimulant medication for ADHD in opioid maintenance treatment. J Dual Diagn 2014;10:32-8.

24 Macleod J, Steer C, Tilling K, et al. Prescription of benzodiazepines, z-drugs, and gabapentinoids and mortality risk in people receiving opioid agonist treatment: observational study based on the UK clinical practice research Datalink and office for national statistics death records. PLoS Med 2019;16:e1002965.

25 Kurdyak P, Gomes T, Yao Z, et al. Use of other opioids during methadone therapy: a population-based study. Addiction 2012;107:776-80.

26 The Swedish National Board of Health and Welfare. Opioid substitution therapy (Swedish: Läkemedelsassisterad behandling Vid opiatberoende). Socialstyrelsen, 2015.

27 Socialstyrelsen. Regulations and general advice on opioid agonist therapy (Svensk: Uppföljning AV föreskrifter och allmänna råd Om läkemedels-assisterad behandling Vid opioidberoende [LARO]), 2017

28 Waal H, Bussesund K, Clausen T, et al. Statusrapport 2017, LAR 20 år. status, vurderinger OG perspektiver, 2017. Available: https://www. med.uio.no/klinmed/forskning/sentre/seraf/publikasjoner/rapporter/ 2018/seraf-rapport-nr-3-2018-statusrapport-2017.pdf

29 European Monitoring Centre for Drugs and Drug Addiction. Addiction EMCfDaD Health and social responses to drug problems - A European Guide, 2017. Available: http://www.emcdda.europa eu/system/files/publications/6343/TI_PUBPDF_TD0117699ENN PDFWEB_20171009153649.pdf

30 Sweden Country Drug Report 2019. European monitoring centre for drugs and drug addiction, 2019. Available: http://www.emcdda. europa.eu/system/files/publications/11354/sweden-cdr-2019_0.pdf

31 The Norwegian Prescription Database (NorPD). Norwegian Institute of public health (NIPH), the Norwegian Institute of public health, 2019. Available: http://www.norpd.no/

32 The Swedish National Board of Health and Welfare. The Swedish prescribed drug register (SPDR): the Swedish prescribed drug register, 2019.

33 ATC Classification Index with DDDs 2018. Who collaborating centre for drug statistics methodology. Oslo, Norway, 2017.

34 The Norwegian Directorate of Health. The Norwegian guidelines for addictive drugs (Norsk: Nasjonal faglig veileder vanedannende legemidler, 2019. Available: https://helsedirektoratet.no/retningslinjer/ vanedannende-legemidler/seksjon?Tittel=oversikt-og-ekvipotens-for5789

35 Dundee JW, McGowan WA, Lilburn JK, et al. Comparison of the actions of diazepam and lorazepam. Br J Anaesth 1979;51:439-46.

36 Muller AE, Clausen T, Sjøgren P, et al. Prescribed opioid analgesic use developments in three Nordic countries, 2006-2017. Scand J Pain 2019;19:345-53.

37 Rosic T, Naji L, Bawor M, et al. The impact of comorbid psychiatric disorders on methadone maintenance treatment in opioid use disorder: a prospective cohort study. Neuropsychiatr Dis Treat 2017:13:1399-408.

38 Maremmani AGI, Pacini M, Maremmani I. What we have learned from the methadone maintenance treatment of dual disorder heroin use disorder patients. Int J Environ Res Public Health 2019;16:447.

39 van Emmerik-van Oortmerssen K, van de Glind G, van den Brink $\mathrm{W}$, et al. Prevalence of attention-deficit hyperactivity disorder in substance use disorder patients: a meta-analysis and metaregression analysis. Drug Alcohol Depend 2012;122:11-19.

40 The National Board of Health and Welfare. Drug treatment of ADHD (Swedish: Läkemedelsbehandling vid ADHD - aspecter av behandling och regionala skillnader. Socialstyrelsen, 2014.

41 The Norwegian Directorate of Health. The Norwegian guidelines of ADHD/Hyperkinetic disorder (norsk: Nasjonal faglig retningslinje for $A D H D)$. Helsedirektoratet, 2018

42 Häge A, Alm B, Banaschewski T, et al. Does the efficacy of parentchild training depend on maternal symptom improvement? results from a randomized controlled trial on children and mothers both affected by attention-deficit/hyperactivity disorder (ADHD). Eur Child Adolesc Psychiatry 2018;27:1011-21.

43 Sheng J, Liu S, Wang Y, et al. The link between depression and chronic pain: neural mechanisms in the brain. Neural Plast 2017;2017:1-10.

44 Woo AK. Depression and anxiety in pain. Rev Pain 2010;4:8-12.

45 Jank R, Gallee A, Boeckle M, et al. Chronic pain and sleep disorders in primary care. Pain Res Treat 2017;2017:1-9.

46 Schjerning $O$, Rosenzweig M, Pottegård A, et al. Abuse potential of pregabalin: a systematic review. CNS Drugs 2016;30:9-25.

47 Norway Country Drug Report 2019. European monitoring centre for drugs and drug addiction, 2019. Available: http://www.emcdda. europa.eu/system/files/publications/11348/norway-cdr-2019_0.pdf 